\title{
REVISITING INNOVATIONS IN ELT THROUGH ONLINE CLASSES: AN EVALUATION OF THE APPROACHES OF 10 MINUTE SCHOOL
}

\author{
Abdul KARIM \\ ORCID: https//orcid.org/0000-0003-2488-8297 \\ BRAC Institute of Languages \\ BRAC University, Bangladesh \\ Dr. Faheem Hasan SHAHED \\ ORCID: https//orcid.org/0000-0003-4381-7478 \\ BRAC Institute of Languages \\ BRAC University, Bangladesh \\ Mohammad Mosiur RAHMAN \\ ORCID: https//orcid.org/0000-0002-6710-8943 \\ School of Languages Literacies and Translation \\ Universiti Sains Malaysia, Malaysia \\ Dr. Abdul Rashid MOHAMED \\ ORCID: https//orcid.org/0000-0001-5300-2876 \\ School of Educational Studies \\ Universiti Sains Malaysia, Malaysia
}

Received Date: 11/02/2018 Accepted Date: 17/05/2018

\section{ABSTRACT}

The ubiquity with regard to technology and availability of social media offered an unorthodox avenue to impart education. Concerning language teaching and learning, the meticulous use of such online platforms has been overtly observed. They become didactic concerning the issue that typical classrooms often exert gaps in terms of students' learning. 10 Minute School, a platform to infuse language teaching and learning through Facebook live classes, undertakes the responsibility to bridge the gaps yielded from traditional English language classroom in an EFL context. The aim of the current study was to carry out a subtle analysis concerning the design of this online learning program in relation to Cognitive Load Theory (CLT) and its implication to e-learning. The study adopted the deductive method of content analysis. The themes have been shaped based on the teaching contents of 10 Minute School. The findings suggested that the approach undertaken by 10 Minute School for its online teaching and learning was instrumental to students' quick learning.

Keywords: EFL, e-learning, online teaching, Facebook, CLT.

\section{INTRODUCTION}

Life in this globalized era has undergone noticeable changes with the advent of technology. Consequently, our concept of education has been witnessing major innovations for the last several years. Flexible delivery of learning materials has been emphasized (Bradshaw \& Hinton, 2004). It has become a cliché for the older teachers to meet students where they are (Manuel \& Schunke, 2016), indicating that classroom is no longer the sole place to impart education. Education, instead, has become pervasive beyond traditional classrooms. The popular way nowadays for disseminating education is online. Considering its feasibility, online teaching has made teachers robust in the changing academia. It is the 
social media where the opulent presence of the $21^{\text {st }}$ century students is blatantly observed (Heiberger \& Junco, 2011), inducing teachers to conduct online classes.

The recent decade has experienced constant discussions subject to the knowledge-based economy that has proliferated pervasive and ever-increasing demand for innovative ways to impart education (Zhang, Zhao, Zhou \& Jr, 2004). According to them, the extraneous demand of new economy for more and more people equipped with new knowledge and skills intrigues the advancement of computer and networking technologies that mean versatile support to thrive learning in a more "personalized, flexible, portable, and on demand manner" (p. 75). Subject to these radical changes in terms of learning needs and technology, a transition has been fueled in modern learning in the era of Internet, which Zhang et al. (2004) have called e-learning. The past few years have been identified as the time for culminating elearning as a potential solution to "lifelong learning and on-the-job work force training" (p. 76). More specifically, e-learning orients technology in learning in which learning materials are disseminated electronically to learners living in the fringe areas via computer network. Concerning their advantages and disadvantages, Zhang et al. (2004) have drawn a distinction between traditional classroom learning and e-learning.

Table 1. Traditional classroom learning and e-learning

\begin{tabular}{|c|c|c|}
\hline & Traditional classroom learning & E-learning \\
\hline Advantages & $\begin{array}{l}\text { - Immediate feedback } \\
\text { - Being familiar to both } \\
\text { instructors and students } \\
\text { - Motivating students } \\
\text { - Cultivation of social } \\
\text { community }\end{array}$ & $\begin{array}{l}\text { - Learner-centered and self- } \\
\text { paced } \\
\text { - Time and location } \\
\text { flexibility } \\
\text { - Cost-effective for learners } \\
\text { - Potentially available to } \\
\text { global audience } \\
\text { - Unlimited access to } \\
\text { knowledge } \\
\text { - Archival capability } \\
\text { knowledge reuse and } \\
\text { sharing } \\
\end{array}$ \\
\hline Disadvantages & $\begin{array}{l}\text { - Instructor-centered } \\
\text { - Time and location } \\
\text { constraints } \\
\text { - More expensive to deliver }\end{array}$ & $\begin{array}{l}\text { - Lack of immediate } \\
\text { feedback in asynchronous } \\
\text { e-learning } \\
\text { - Increased preparation time } \\
\text { for the instructor } \\
\text { - Not comfortable to some } \\
\text { people } \\
\text { - Potentially more frustration, } \\
\text { anxiety and confusion. }\end{array}$ \\
\hline
\end{tabular}

According to Fisher, Exley and Ciobanu (2014), e-learning becomes the part of majority of classrooms. It is integrated and emphasized since it precedes formal and informal interaction between teacher and students and among students themselves. Moreover, it shuttles encouragement to spell student-oriented classrooms. Balcikanli (2009) defines online learning as a model of instruction that includes the use of computer technology to enrich and support pedagogy. In particular, teaching, learning and assessment, important pedagogical components, get flourished due to the advent of it.

The channels or tools of e-learning range widely. This incorporates the application of Web 2.0 technologies including social networking sites namely Facebook, Instagram, Twitter, LinkedIn etc., blogs, video sharing sites, and web applications (McCarthy, 2010; Tina, 2010). It is evident in literature that e-learning has a positive impact in all the disciplines of education. E-learning tools have been incorporated successfully in mathematics education (e.g., Tang \& Yu, 2018; Watted \& Barak, 2018; 
Kabilan, Ahmad \& Abidin, 2010). Such inventive technologies open avenues for people to exchange knowledge, participate on online meeting and undertake discussion in real time, which were impossible hitherto for a learning environment (Ru-Chu, 2013).

\section{Facebook as the Medium of Language Teaching and Learning}

In order to keep our scope specific, under the broader umbrella of e-learning, we have focused on Facebook as the medium of e-learning in this article, in relation to language teaching and learning in the contexts where English being spoken as a foreign language. Facebook is the most popular social networking sites with 2.13 billion active users (Facebook, 2017). Mark Zuckerberg, a Harvard student, was its pioneer. Along with a few classmates, he designed Facebook in 2003, and it was launched in 2004 (Stone, 2006). It is privately owned by Facebook, Inc., and freely accessible social networking site. According to Boonkit (2011), it acts as a platform for an organization such that a school or business, helping members to identify each other. FACEBOOK is the registered trademark of Facebook, Inc (Facebook, 2011). Moir (2010) identifies Facebook as a popular tool since it creates an interactive platform for all irrespective of their groups, age, gender, thought and intention. Red (2009) reports, Facebook facilitates business contact and global communication among Facebook members. Concurrently, Facebook becomes the vehicle for imparting education in various English as a Foreign Language (EFL) and English as a Second Language (ESL) settings (Kabilan, Ahmad \& Abidin, 2010). It creates another dimension concerning e-learning (Pimmer, Linxen \& Gröhbiel, 2012). One of the startling features of Facebook is the 'live' option that often intrigues language teachers to conduct live classes. Of particular benefit yielded is the frequent interaction between mentor and students, getting their questions answered, which often teacher fails to address in the classroom due to inadequate time. As such, it is conspicuous that Facebook is conducive to infuse education with particular concern to English Language Teaching (ELT) in EFL and ESL contexts. Admitting it as another form of online teaching and learning, investigation into the impact of such teaching on students' achievement is pertinent to conduct. Boonkit (2011) also figures out the paucity of research subjected to the adaptation of teaching and learning on Facebook in EFL and ESL settings. Although few in number, the studies conducted so far indicate positive outcome with regard to Facebook classes. For instance, Simpson (2017) carries out a study concerning the effect of Facebook writing classes on students' writing skill development. The investigation reveals that students experience improvement in their writing skills as a result of the Facebook classes. Boonkit's (2011) study also depicts that Facebook enables students to apply English to accomplish daily worldly affairs. However, the present study undertakes the investigation into the design and presentation of the learning materials of 10 Minute School, a language class conducted on Facebook live, in relation to Cognitive Load Theory (CLT) and its implication to elearning.

\section{THEORIZING E-LEARNING}

The current study concerns the CLT which, as sketched by Van Marrienboer and Ayres (2005), has a pragmatic implication subject to e-learning. The following section will primarily highlight CLT. Finally, it will present the implication of CLT in relation to e-learning. This vignette provides us with the ground to carry out subtle analysis with regard to 10 Minute School, an e-learning platform.

The CLT (Sweller, 2004) assumes a working memory and long-term memory. Working memory has limited capacity when processing novel information. Long-term memory, on the contrary, retains cognitive schemas. Cognitive schemas generate knowledge that gravitate human expertise. In essence, expertise develops through the conscious and mindful construction of complex schemas, and through the automation of some of those schemas (Van Marrienboer \& Ayres, 2005). They explicate that in working, there are seven elements that activate information storage and two to four elements responsible for processing information. However, long-term memory is free from such type of limitation. Below is a diagram presenting clearly the features concerning CLT. 


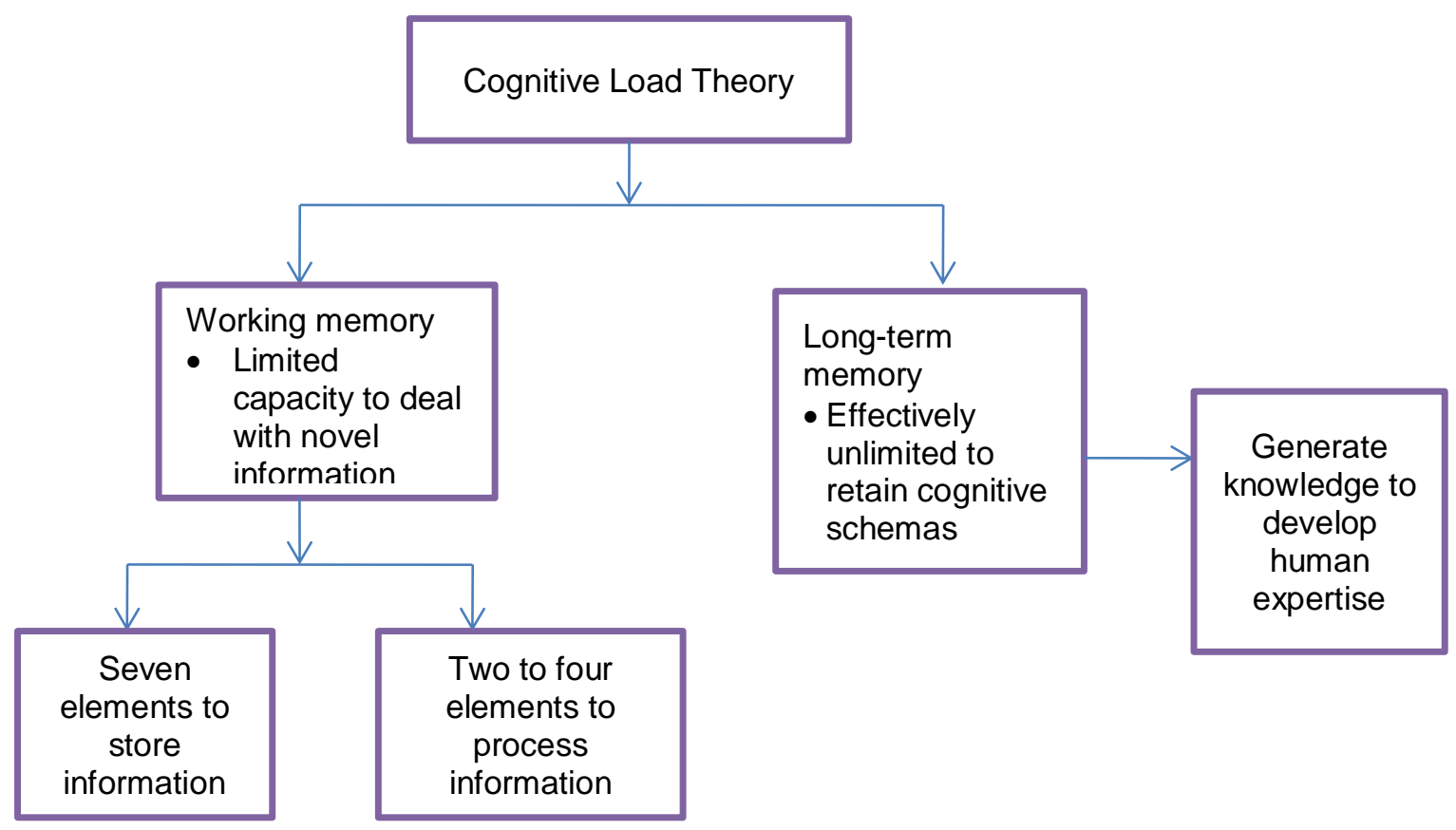

Diagram 1: Features Cognitive Load Theory and their functions

Schemata help to organize and store knowledge, and substantially lower working memory load. Now the question is, how do schemata operate it? While dealing with information that is organized in schemas and is related to prior knowledge, the pressure of working memory load for processing that information becomes substantially reduced. At that time, the capacity of working memory is potentially extended. However, in converse phenomenon, the capacity of working memory experiences difficulty to process novel and unorganized information because it is challenging to place unorganized information in organized form. Even the capacity of the working memory seems insufficient when it deals with a large amount of information. Therefore, we can conclude that working memory can process information relevant to schemata; however, it experiences problems to deal with unorganized and large amount of information. Given below is a table depicting the state of working memory in different situations.

Table 2. The state of working memory in different situations

\begin{tabular}{ll}
\hline Process with ease when dealing with organized information relevant to prior \\
knowledge. \\
Process with difficulty when dealing with unorganized and large amount of \\
information.
\end{tabular}

Van Marrienboer and Ayres (2005) note that working memory can process information faster if the pertinent knowledge derived from schemata is circulated quickly. They discuss about the automation of schemata, meaning the quick construction of the relationship between knowledge stored in schemas and knowledge to be processed. "Schemata may be automated if they are repeatedly and successfully applied" (p. 6). To exemplify, we can talk about the acronyms including DM, ALM, TPR or CLT that are often used in the field of ELT. These terms are easily apprehended by teaching practitioners or teacher educators because they have frequent usage of these acronyms. On the contrary, practitioners from English literature and linguistics background certainly fumble for a while to understand these terms, although they have gone through such studies. Therefore, we can summarize that when knowledge from schemata is frequently used, memory can process information easily by relating to the prior knowledge. Certainly, at one phase, automation takes place - preceding the quick relation building 
and processing of information. CLT suggest to design the instructional contents in a way that individual can process it with ease by relating the contents with the prior knowledge.

According to Van Marrienboer and Ayres (2005), factors affecting the working memory load are "the intrinsic nature of the learning tasks themselves (Intrinsic Cognitive Load), the manner in which the tasks are presented (Extraneous Cognitive Load), or the amount of cognitive resources that learners willingly invest in schema Construction and automation (Germane Cognitive Load)" (p. 6). The diagram below shows the affective factors for working memory load.

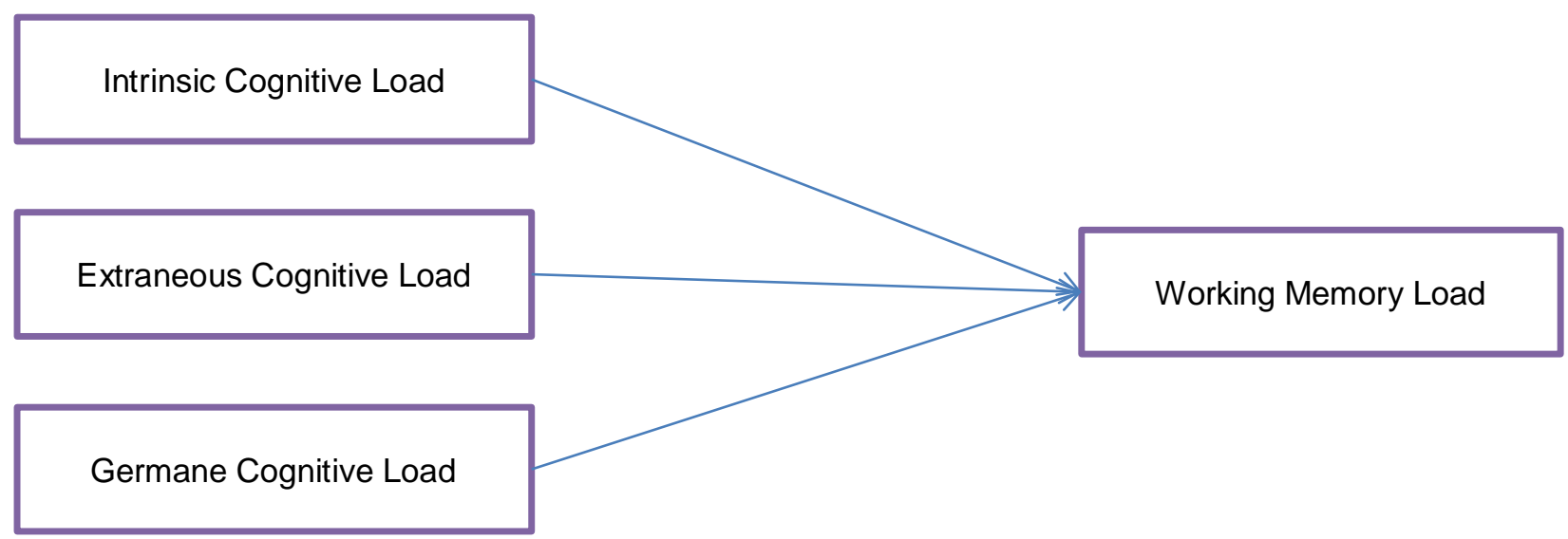

Diagram 2. Factors affecting working memory load

Intrinsic Cognitive Load is "determined by the interaction between the nature of the materials being learned and the level of expertise of the learner" (p. 6). It depends primarily on the number of elements that must be simultaneously processed in the working memory, which in turn, depends on the extent of element interactivity of the material or task that must be learned. Van Marrienboer and Ayres (2005) note that materials with high interactivity are difficult for the working memory to process. The only way, as they elaborate, to understand is enrich schemas that are responsible to regulate interacting elements. It means that individual with rich schemata can incorporate a large number of interacting elements, whereas one with low schemata cannot even process an element. Below is a diagram illustrating the production of Intrinsic Cognitive Load. 


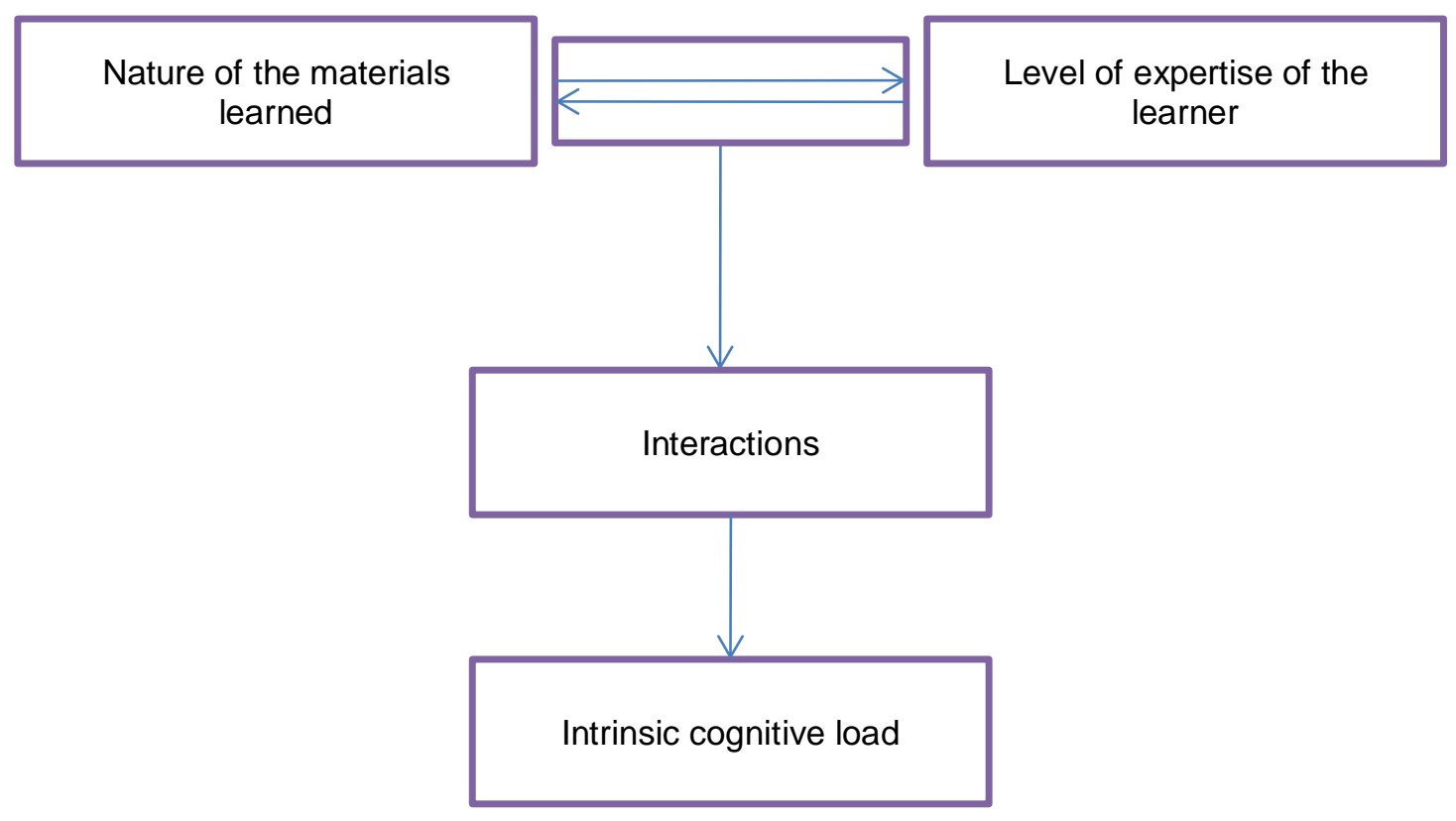

Diagram 3. The production of Intrinsic Cognitive Load

In contrast, Extraneous Cognitive Load entails processes that are not directly required for learning, and can be altered by instructional interventions. Such load is yielded from using weak problem solving methods, scattered distribution of information concerning time and place, and searching for information to complete a learning task given in instructional materials.

Germane Cognitive Load involves the processes that are inevitable in leaning. It incorporates schema construction and automation that are identified engaged directly to learning. Unlike the processes involved in extraneous cognitive load, the processes associated with Germane cognitive load stimulate the construction and automation of schemata that precede learning. Van Marrienboers and Ayres (2005) report that various problem solving situations lead learners to construct cognitive schemas because it help learners to acquaint with different situations, and at one point they become identical to the learners. In other word, by repeatedly experiencing different situations, learners become familiar to these situations. As such, learners' working memory can process information quickly. High variability intrigues learners to invest more effort in learning. That is how learners' cognitive schemata can be increased.

\section{Implication of CLT in Relation to E-learning}

It has been observed that many e-learning applications are designed incorporating complex learning tasks which symbolize the character of a large number of interacting elements. Concerning conceptualization, such tasks requires simultaneous functioning in working memory in order to reach understanding level. Likewise, concerning skills development, tasks pertaining to skills require learners' working memory to coordinate in order to secure their coherent performance. Van Marrienboer and Ayres (2005) show that the removal of extraneous cognitive load cannot solely assure efficient learning because materials with high interactivity may often lower the effectiveness of learning. Consequently, embracing the phenomenon, they call for avoiding the presentation of all information at once. They exemplify that one may present relevant element information with a few interaction, and then move forward to adding more tasks/materials/contents/information that require more interactions. Similarly, simple version of the task should be presented first, and then, more and more complex versions of the tasks should be employed. Van Marrienboer and Ayres (2005) call it progressive methods which primarily alter intrinsic cognitive load. Adopting this method, the element interactivity of the materials is artificially lowered in the early stage of instruction. Below is an illustration depicting the avenue for schemata construction in e-learning. 


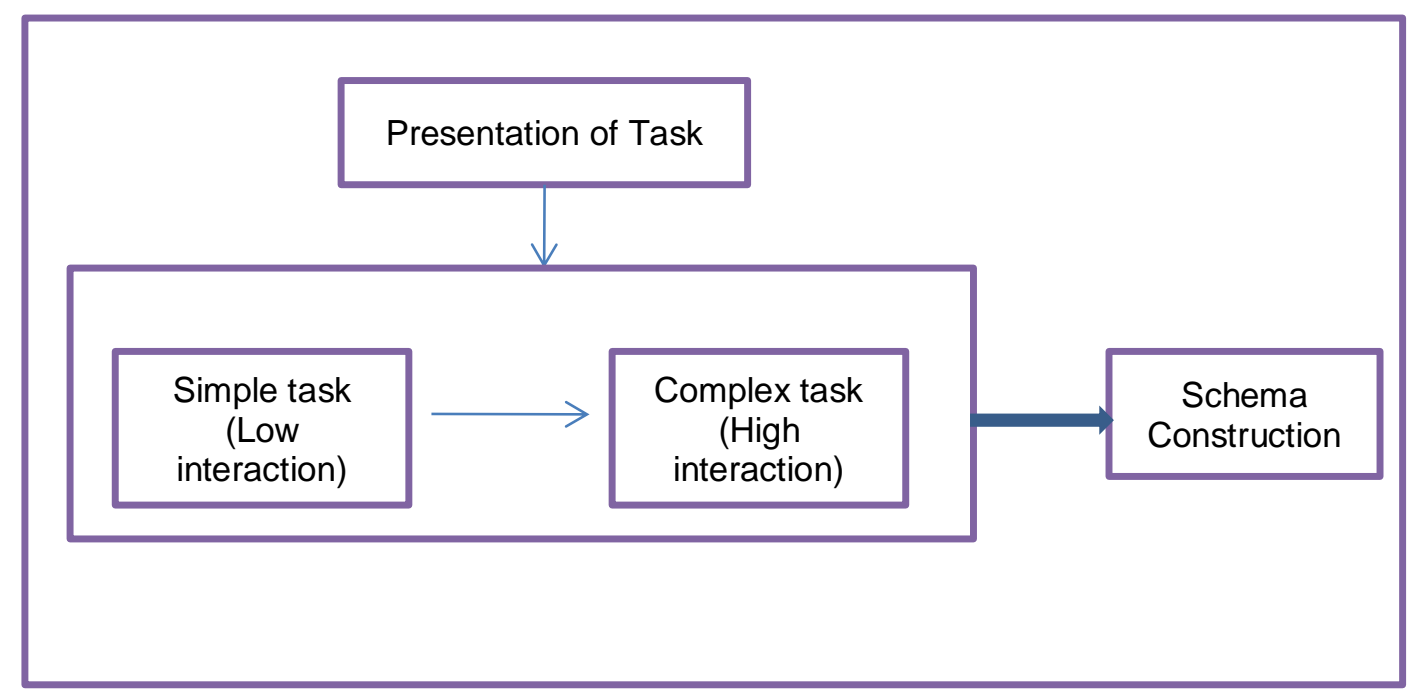

Diagram 4. Implication CLT to e-learning

\section{The Aim of the Study}

The present study was based on an e-learning school named 10 Minute School in Bangladesh. The medium of instruction of the school is bilingual, both native Bangla and target language English were used in instruction. The aim of the study was to examine online learning offered by 10 Minute School that have been endeavoring to conduct language classes on Facebook using its new tool called Facebook live in order to improve learners' grammatical knowledge.

\section{THE STUDY}

The current study accounted a subtle analysis concerning the design of this online learning program in relation to CLT and its implication to e-learning.

\section{Minute School}

10 Minute School, founded by Ayman Sadiq, a Bangladeshi educator and entrepreneur, is the largest online education platform that imparts lessons concerning academia, skills development and profession. A leading telecom company Robi is the official sponsor of this school. It has produced over 4000 video lessons, which provide more than 150,000 students with education every day. It decentralizes education with ease and secures quality education by designing and presenting contents so that anyone can learn anything, at any time, from anywhere, completely free of cost. It harnesses its own materials. The classes are, to a greater extent, subjected to preparing students for their Junior School Certificate (JSC), Secondary school Certificate (SSC) and Higher Secondary Certificate (HSC) examinations. Additionally, it designs classes on preparation for admission tests for higher education and skill development. Professional courses are also conducted by this school. On top of these, it disseminates motivation among the youths so that they can be conducive to national development, and be instrumental to the national dream 'digital Bangladesh', a dream of the current government headed by the current Prime Minister of Bangladesh Sheikh Hasina, daughter of the father of nation Bangabandhu Sheikh Mujibur Rahman. The Deputy Minister of Information and Communication Technology Junaid Ahmed Khan acknowledges the activities of 10 Minute School and commits to provide with adequate support to expand it in future. For being the pioneer of 10 Minute school and contributing to the national education, Ayman Sadiq has been awarded with Queen's Young Leader Award for 2018.

Teaching materials exploited in 10 Minute School concern the preparations for JSC, SSC and HSC examinations. Besides, it has incorporated skill-development components and professional development courses. English teaching is ubiquitous in 10 Minute School, addressing the needs of the learners. To elaborate, it has addressed the English syllabi for JSC, SSC and HSC, equipping the learners according to their need. In skill-development section, it has also subsumed English but in different shapes. For 
instance, the practical usage of English is highly emphasized here. Presentation and communication skills, interview skills, and CV writing skills constitute teaching of English in this section. The professional courses encompass spoken English, business English, interview skills and CV writing to equip learners.

Our intention in this article was to draw attention only on the grammar classes conducted to enhance grammatical accuracy of the learners. The grammatical items consist of parts of speech, subject verb agreement, right form of verbs, articles, tag questions, appropriate preposition, tense, conditional sentences, transformation of sentences, voice, narration, idioms and phrases, and modifier. It addition, English classes also addresses common mistakes in English, error finding, spoken English, building vocabulary knowledge, group verbs, common English expressions and grammar redundancy errors. These are the items taught on Eacebook live classes. Moreover, based on materials taught, the problem solving classes are also arranged on a regular basis, where students raise questions and get their questions answered. To assess learners' attainment, grammar game is also arranged, in which winners are rewarded with special gift packet, sponsored by Robi. On top of that, the Facebook live classes are uploaded on You Tube so that learners who miss the live class can be privileged by watching them later from You Tube. Coupled with this, learners who participate in the live class can also watch the classes later on with a view to attain more mastery.

\section{The Method}

The aim of the study was to carry out a subtle analysis concerning the design of 10 Minute School online learning program in relation to CLT and its implication to e-learning. In order to conduct the investigation, this study has drawn on the theoretical framework suggested by Van Marrienboer and Ayres (2005). The major themes have been developed to analyze the 10 Minutes School's content of teaching and discussed in relation to its implication in learners learning. Content analysis can be conducted inductively and deductively (Elo\&Kyngäs, 2008). The present study adapted deductive method of content analysis where the themes of analysis - based on the theoretical underpinningshave been developed. And in terms of these criteria, the contents of 10 Minute School have been analyzed critically. Contents like YouTube videos, blog, Facebook materials and website materials have been analyzed. These data are available publicly in 10 Minute School website, Facebook Page (www.facebook.com/10MinuteSchool), YouTube Channel (www.youtube.com/ 10minuteschoolenglish). Public document is validated data since it is already in the public domain (Stake, 1995), therefore, to address the validity and reliability issue regarding secondary data collection, we have provided links of all the available content/materials of Ten minutes school that are hosted in the website. Moreover, as the program is an online program, the website will be considered the as the sole source of data.

\section{FINDINGS OF THE STUDY}

This section highlights the development of teaching grammar in 10 Minute School. In addition, it subsumes a scrutiny, in relation to the CLT and its implication to e-learning, concerning the patterns which 10 Minute School incorporates in teaching and learning. To accomplish this, we sequentially present the components taught in 10 Minute School and the teachers' ways of teaching them. And subsequently we relate the happenings of each class to CLT and its implication to e-learning to measure the extent to which the underpinning ideology of grammar classes matches with that of CLT and elearning. To ensure a blatant view, we sectionalize our findings under themes.

\section{Parts of Speech and Articles}

The idea that underpins the organization of grammatical items is simplicity to complexity. It is assumed beforehand that participant students are beginners, irrespective of their levels-e.g. primary, secondary and higher secondary - in grammar learning process. Parts of speech, the topic of its first class, are taught to introduce pupils to noun, pronoun, verb, adverb, adjective and so on. Consequently, students can build their knowledge about different parts of speech. Though e-learning concerns learning beyond classroom teaching, students are still acquainted with parts of speech in the classrooms. Therefore, they 
have schemata regarding these. Subsequently, when they are taught on Facebook live class, their working memories experience little or no difficulty to process and store information. Apprehending Van Marrienboer and Ayres' (2005) elaboration, it becomes conspicuous that because of their prior knowledge about parts of speech, they can organize and store the input easily from online class. As a result, the pressure of working memory of learners becomes potentially reduced. In other words, the intrinsic cognitive load seems to be lowered since learners require low interaction to understand the content. The plausible consequence is the enrichment of learners' schemata, given they have prior exposure to the same lesson in the conventional classroom, and are incorporating relevant information, according to Van Marrienboer and Ayres' (2005) view.

Moreover, we observe the exercise of germane cognitive load, integrating schema construction and automation simultaneously. Students' prior knowledge ideates about what they are learning, and at the same time, they enrich their schemata-leading them to perform further learning.

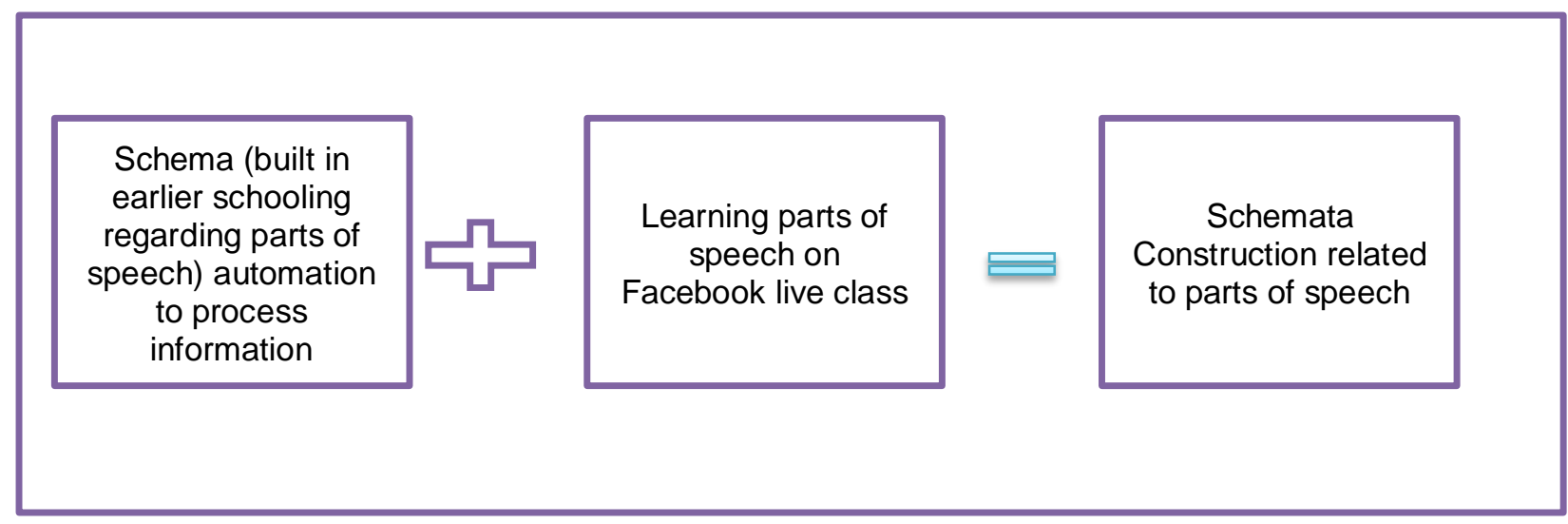

Diagram 5. Schemata Construction related to parts of speech

Followed by parts of speech class are classes to teach pronoun, adjective and appropriate preposition. The sequence is worth reducing the pressure of learners' working memory, provided that in first class they have enriched their schemata regarding parts of speech. In these classes teachers elaborate on pronoun, adjective and appropriate use of prepositions. Prior knowledge of the learners accelerates quick learning for them. In the following class, the topic is article. Two classes are designed to teach articles. The first class starts with describing two types of article - definite (the) and indefinite $(a$, an). Teacher explains with example like, I want a book and $I$ want the book. He uses as many examples as possible to bring ease in learning. Teacher also clarify the fact that when article in a sentence becomes the parts of speech. He exemplifies writing a sentence I have a book. Then, he asks the students what parts of speech $\underline{a}$ is. Students, building on their schemata developed in the first class, elicit that $\underline{a}$ here is adjective since adjective deals with number. So, the automation of schemata is blatantly observed here. One thing to be noted that prior to explaining any part, teachers asks students about what they know about the particular component. Likewise, before explaining the use of a/an, he asks them based on what we use them. He provided options including,

\begin{tabular}{|cl|}
\hline a. & Vowel \\
b. & Consonant \\
c. & Vowel and consonant \\
d. & Lound \\
e. & Both a and b \\
F & According to your wish \\
\hline
\end{tabular}


Such act of the teacher precedes another dimension of schemata automation. For instance, immediately after the question is raised, students recall the information extracted by them in their primary level that the use of a/an is determined by vowel and consonant sounds. After getting the answer, teacher explains why it is based on vowel and consonant sound. This 'why' is the additional information added to students' current schemata, and that is how schemata are built. The second class for article teaching concerns more explanations, question-answer session and practice. Students have no chance to watch the class sitting idle; rather the class is interactive, and incorporates schemata automation and construction.

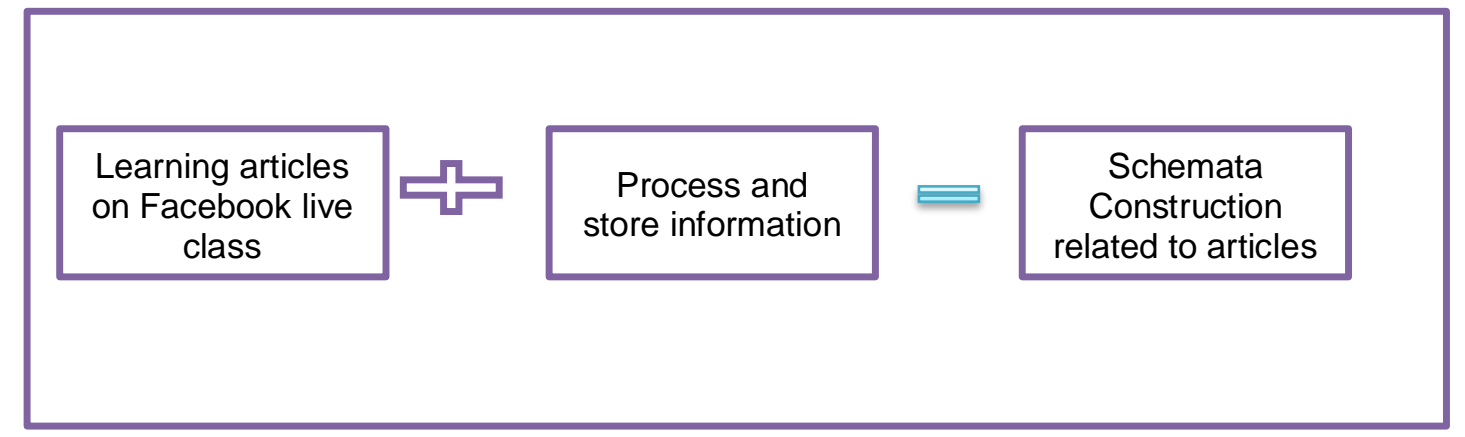

Diagram 6. Schemata Construction related to articles

\section{Subject-Verb Agreement}

10 Minute School Designs the topic for the following class incorporating subject-verb agreement. Since the primary level of schooling in Bangladesh students are acquainted with number, person and so on, it becomes easier for them to grasp the information. Teacher also seems to ask them to recall their knowledge about number and person, and relate it to the concerning topic. As such, the automation of schemata consolidates learners' understanding. The schemata building in this class regards the idea of principle verb and auxiliary verb. Teacher here exemplifies with the sentence I am driving my new car. Consequently, besides teaching them relevant topic, teacher provides them with a hint of present continuous tense by using verb+ing, which offer a prior knowledge about a subpart of tense. In addition, he draws students' attention on common auxiliary verbs for singular and plural number, which later assist them when learning tense. Like other class, after teaching each component, teacher offers some exercises that are done by the students. The added advantage yielded by such initial assessment is that it notifies teacher whether or not students learn properly. Apart of the common rules, teacher also sheds light on having as well as, beside, along with, and accompanied by after the main subject. For instance, He along with his business partners has attended the meeting; I as well as my friends am going to concert; The PM accompanied by his ministers is having lunch; Fabiha, beside her friends was present in the session. Accordingly, learners, besides learning subject-verb agreement, can also recall their knowledge about preposition. Moreover, teacher shows them a trick, known as 'ignore', indicating that students should ignore the part associated with. Instead, they have to focus on the subject before them, and use verb/auxiliary verb according to it. This trick here concerns their schemata construction. When teacher starts teaching the rule regarding either-or and neither-nor with the subject, students can recall their knowledge about conjunction. When he teaches subject-verb agreement in the case of collective noun, countable noun and non-countable noun, learners can shed light on prior knowledge about noun, which is learned in the first class. The teaching of unusual rules for having subjects including food, meat, furniture, soap, bread and utensil etc. constructs their schemata. Like other classes, students raised their questions, and get them answered by the teachers to remove their confusion. 


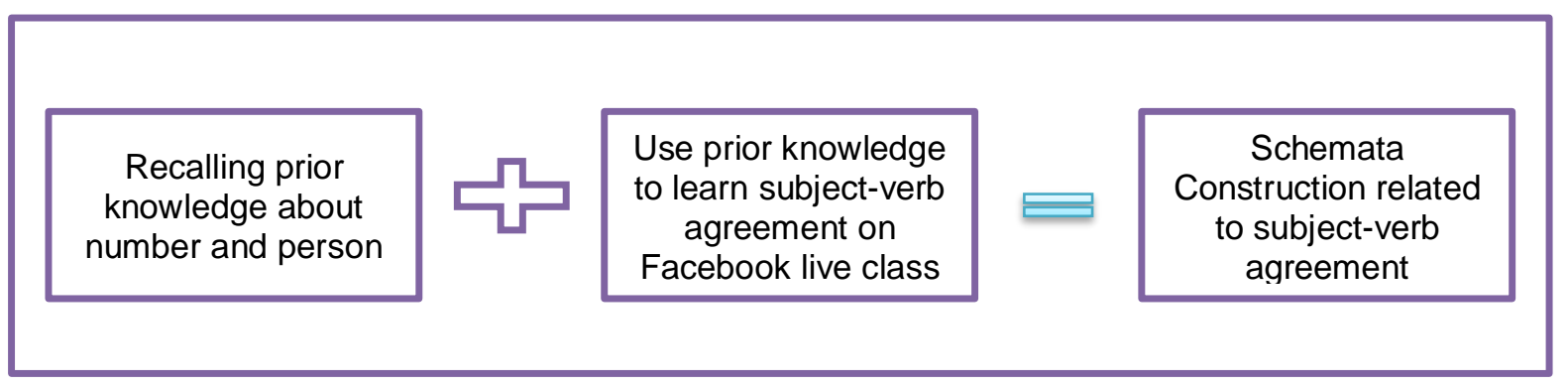

Diagram 7. Schemata Construction related to subject-verb agreement

\section{Tense and Conditional Sentences}

The following two classes are arranged to teach tense. At the beginning of the first class, teacher explains that tense is an essential component of English grammar. To learn translation, narration, transformation and voice, the importance of tense is inevitable. Teacher first asks students to recall what they learn about tense in their secondary schooling. Thus, we experience the essence of schemata automation. Then, teacher presents a definition and classification of tense, added as new information to learners' current knowledge about tense. After that, he elaborates in the phenomenon to be considered as present indefinite tense. Followed by this is the elicitation of sentence structure for present indefinite tense. When he illustrates by using examples, students recall their knowledge regarding subject-verb agreement. Subsequently, he focuses on present continuous tense, present perfect tense and present perfect continuous tense with respective sentence structures of these and examples. He also prepares tasks for students to solve. Learners need to use the sentence structures they have learned and have frequent application of subject-verb agreements. Likewise, they are taught past indefinite, continuous, perfect and perfect continuous tenses. As such, schemata building in this class concerns learning the rules and their application to describe different phenomena occurred in present and past.

The second class of tense is designed to teach future tense and conditional sentences. Teacher at the beginning writes down the structures of future indefinite tense. With examples, he makes students understand it. Following same techniques, he teaches future continuous, perfect and perfect continuous tense. It is noteworthy that it takes relatively less time to teach and equip learners with the structures of future tense. Considering Van Marrienboer and Ayres' (2005) elicitation, we can conclude that because of the schemata constructed by them regarding present and past tense, students easily apprehend future tense. Schemata automation and construction take place simultaneously. According to their view, working memory processes information quickly if the relevant knowledge is automated faster.

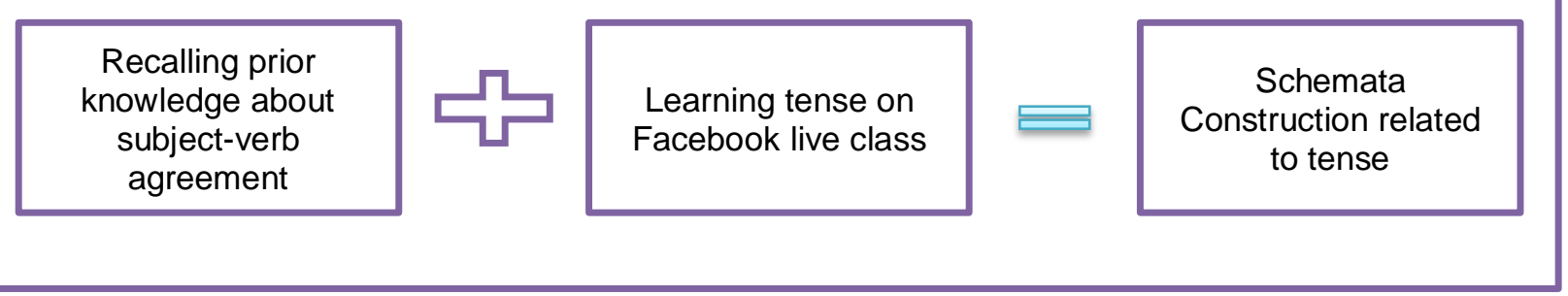

Diagram 8. Schemata Construction related to tense

Then, teacher moves to the next topic of this class which is conditional sentences. Beside the current one, another two classes are designed to teach real conditions, and present unreal and past real conditions. Learning tense beforehand reduces the pressure of pupils' cognitive memory because the organized information in schemata facilitates their learning of conditional sentences. Therefore, they have adequate capacity in their working memory to process and store information. At times, they need little interaction, and accordingly, their intrinsic cognitive lead is substantially lessened. We also observe the absence of extraneous cognitive load as a result of proper instructional approach to solve problems and sequential presentation of information. However, we found the exhibition of germane cognitive load. Learners are seemed to invest their schemata willingly to accomplish their learning. 


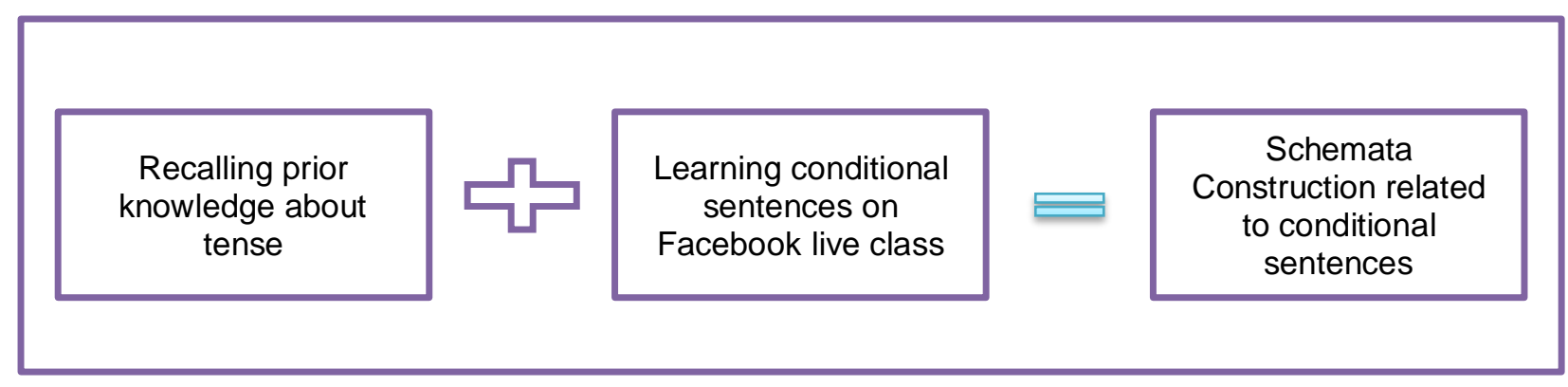

Diagram 9. Schemata Construction related to conditional sentences

\section{Voice}

The topic for the next two classes is voice. Teacher begins the first class mentioning types of voice and the basic difference between them. This is the additional information added initially to learners' schemata. After that, to test students' current command regarding voice, teacher offers some tasks and gives them some time to solve them. After getting students' answer, he starts his main lecture. He follows a 'tense by tense' sequence. To maintain the order like, 'simplicity to complexity', teacher first shows how to change voice for present indefinite tense, and followed by this, he teaches how to change voice for past indefinite tense. Subsequently he focuses on the voice change related to present continuous tense. Then, he concerns past continuous tense so that both of them follow same structures with only difference pertinent to auxiliary verbs. Such initiative of the teacher lowers the pressure of learners' working memory and allows it to process information quickly. Accordingly, learners' schemata get automated and precede their learning. Here, they have the opportunity to shed light on their knowledge about tense, subject-verb agreement, number, subject and object pronoun, and so on. To test learners' understanding, teacher gives them some sentences to change voice.

The teacher then moves to teach how to change voice for present perfect tense, and subsequently, teaches past perfect tense. Avoiding the usual sentence regarding past perfect tense, he first exemplifies with simple sentence such as, They had completed the assignment. After that, he moves to the change of voice concerning future indefinite tense. Then, he teaches how to change voice for future continuous and future perfect tense. Learners are seemed to exhibit quick understanding because of their schemata about tense, and the rules to change voice that teacher shows them up to past perfect tense.

In the next class, teacher shows the rules to change voice concerning interrogative sentence. The exhibition of students' schemata usage is observed in this class. Since they know about the rules to change voice for assertive sentence, they easily embrace the rules for interrogative sentence. In this class, teacher also allows students to ask questions to clarify their confusion. To make the class interactive, he assigns some tasks and appreciates the correct answer providers.

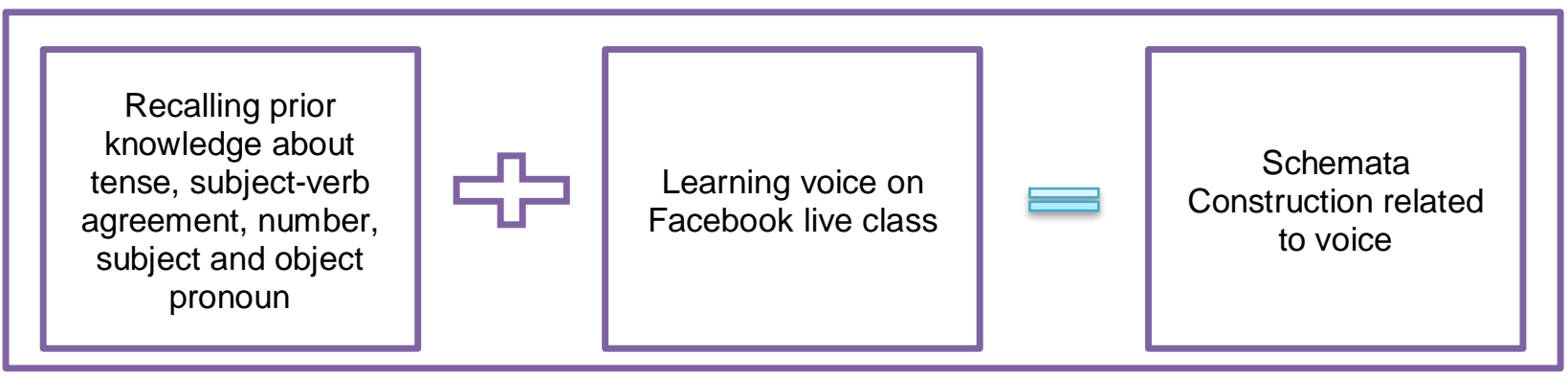

\section{Narration}

Diagram 10: Schemata Construction related to voice

The next two classes concern teaching and learning of narration. Teacher at the beginning defines narration with familiar examples so that students can understand well. He also explains reporting verb and reported speech because these are the frequently used terms in such lesson. Students immediately 
add them as new information to their schemata. To maintain the sequence 'simplicity to complexity', teacher first teaches direct and indirect speeches that entail present indefinite tense. After that, he moves to more complex parts. Application of learners' prior knowledge related to tense is found omnipresent. To create an interactive session, teacher assigns tasks after teaching each rule. In the next class, teacher shows how to solve passage narration. Their schemata constructed in the first class are instrumental for learning in the second class. They have no intrinsic cognitive load. However, students seem to invest their schemata willingly in this class, the fundamental idea of germane cognitive load.

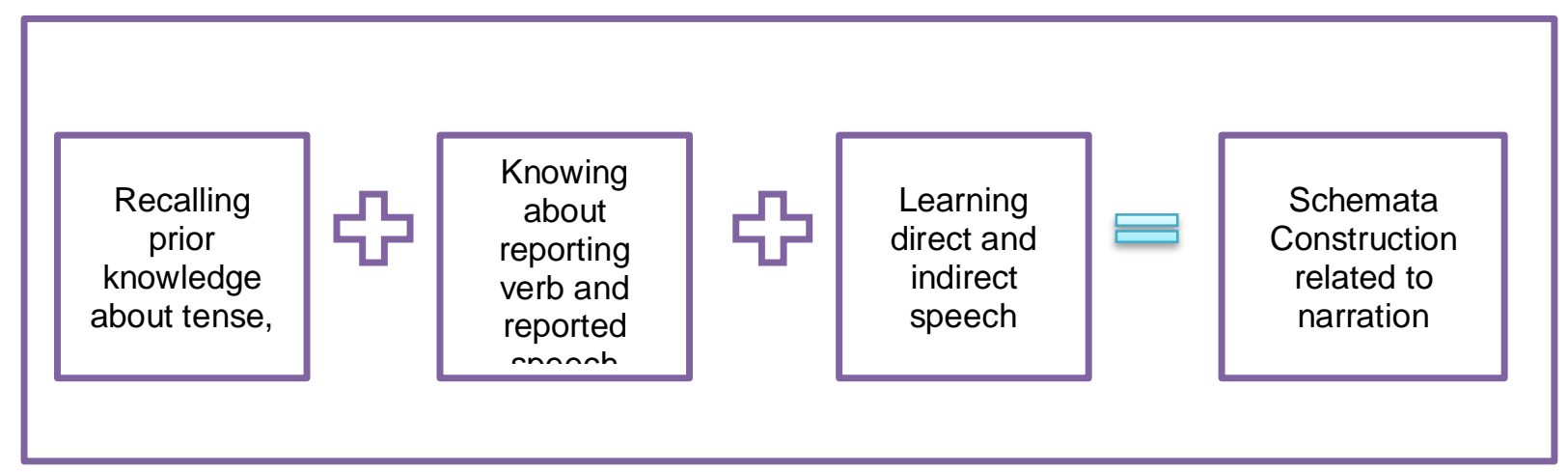

Diagram 11: Schemata Construction related to narration

\section{Transformation}

The next topic is transformation. Three classes are designed to teach transformation. In the first class, teacher shows them how to transform from assertive sentence to interrogative sentence and from assertive sentence to imperative sentence. At the beginning, he presents an overview regarding assertive, interrogative and exclamatory sentences so that students' working memory can process further information quickly. Then, he shows the transformation of sentence from assertive to interrogative. After that, he discusses the transformation of sentence from assertive to exclamatory. Conversely, he also teaches the transformation of sentence from exclamatory to assertive and from interrogative to assertive. In addition, adopting 'simplicity to complexity', he teaches transformation of sentence from positive to negative sentence. He also presents some exceptions including, I must punch Ayman in the face $\rightarrow$ I cannot but punch Ayman in the face, Every student loves Fabiha $\rightarrow$ There is no student but loves Fabiha.

The whole session is full of interaction and practice. Students' schemata construction here regards transformation of sentence from assertive to interrogative, from assertive to exclamatory and from positive to negative. Since the teacher presents the simple tasks first, and then, moves to more complex ones, the working memories of the learners process and store information without experiencing difficulty.

The second class includes transformation of sentence from assertive to imperative and assertive to optative. Teacher first provides an overview of imperative and optative sentences to build learners' schemata. Then, he shows the transformation of sentence from assertive to imperative and from assertive to optative, and assigns tasks to assess learners' understanding. Actually, teacher writes few sentences and asks students to transform them from assertive sentence to imperative sentence and from assertive sentence to optative sentence. For example, teacher writes You should do the work and May you shine in life. Students are asked to transform them, as instructed. After getting the tasks done by the students, teacher focuses on transformation of simple, complex and compound sentences. First, he introduces students to simple, complex and compound sentences. Learners, therefore, come to know about main clause and subordinate clause. This prior information precedes the working memory to process and store further information. Here the learners have to recall their prior knowledge about preposition, conjunction and relative pronoun. Maintaining the sequence of 'simplicity to complexity', teacher accomplishes teaching. He also assigns tasks after completing each component. 
The final class entails teaching of transformation from positive to comparative, positive to superlative and vice versa. Like previous two classes, teacher follows the 'simplicity to complexity' sequence, and thereby, facilitates learners' working memories to process information quickly. Tasks are assigned and question-answer session is allocated in order to secure students' learning. To elaborate, teacher writes Rahim is the prettiest boy in 10 Minute School and Monalisa is one of the greatest portraits in the world, and asks students to transform them from superlative to positive and comparative.

\section{Parallelism and Dangling Modifier}

The following class has incorporated grammar parallelism and dangling modifier. Grammar parallelism requires learners' prior knowledge related to subject-verb agreement, tense, voice and parts of speech. Since the previous classes substantially construct learners' schemata regarding these, learners are able to grasp it quickly. The automation of schemata enables them to understand rules, and builds their schemata that are pertinent to grammar parallelism. After that, teacher focuses on dangling modifier. At first, he introduces learners to modifiers with examples. The application of parts of speech, subject-verb agreement, tense and voice, stored in learners' schemata, is observed throughout the session.

\section{Tag Questions}

In the following class, students are taught tag questions. First, teacher discusses the necessity of tag questions. This is new information added to learners' schemata. Throughout the learning process, learners are required to invest their schemata including tense, auxiliary or linking verbs. Teacher teaches rules that concern tag questions. Teacher discusses the rules using multiple examples so that learners' working memory can process and store information quickly.

\section{Right form of Verbs}

The last class involves discussion regarding the right form of verbs. Learners' schemata entailing subject-verb agreement, voice, tense, narration and gerund shapes a base to learn it quickly. To grab students' attention, teacher begins the class with a task 'He speaks as if he (know) everything'. Most of the learners answer correctly using their schemata. Like other classes teacher maintains 'simplicity to complexity' sequence. The application of germane cognitive load is observed here. Learners invest their schemata to learn it quickly.

\section{Error Finding and Revision}

Two classes are designed to revise what had been learned so far. At the beginning of the first class, teacher states that this a class to revise and check whether or not there is any gap associated with learning. Therefore, revising the learned components and bridging the gaps are the fundamental concern of these classes. Teacher writes erroneous sentences in the following way and asks students to find the error/s.

Table 2. Sentences formed to assess learners' understanding

Buying clothes are often a very time-consuming practice because those clothes that a person likes are rarely the ones that fit him or her.

Because they had spent too many time considering the new contract, the students lost the opportunity to lease the apartment.

These televisions are all too expensive for we to buy at this time, but perhaps we will return later.

George has not completed the assignment yet, and Mariya hasn't neither.

After George had returned to his house, he was reading a book.

Many theories on conserving the purity of water has been proposed, but not one has been as widely accepted as this one.

The food that mark is cooking in the kitchen is smelling delicious.

Daniel said that if he had to do another homework tonight, he would not be able to attend the concert.

It has been a long time since we have talked to John, isn't it?

The work performed by these officers are not worth our playing them any longer. 
Teacher asks student to find error from the underlined parts. The intention is to assess students' confidence concerning their learning - given not all the underlined parts are erroneous. The automation of their schemata assists learners to identify errors associated with the aforementioned sentence.

\section{DISCUSSION}

From the above-mentioned investigation into 10 Minute School in relation to CLT theory, it is realized that the approach which the 10 Minute School has undertaken for its online teaching and learning substantially facilitates students to learn quickly. Below is an illustration drawn by adapting CLT and it implication to e-learning, indicating that 10 Minute School juxtaposes its components adopting the suggestion yielded by CLT and e-learning.

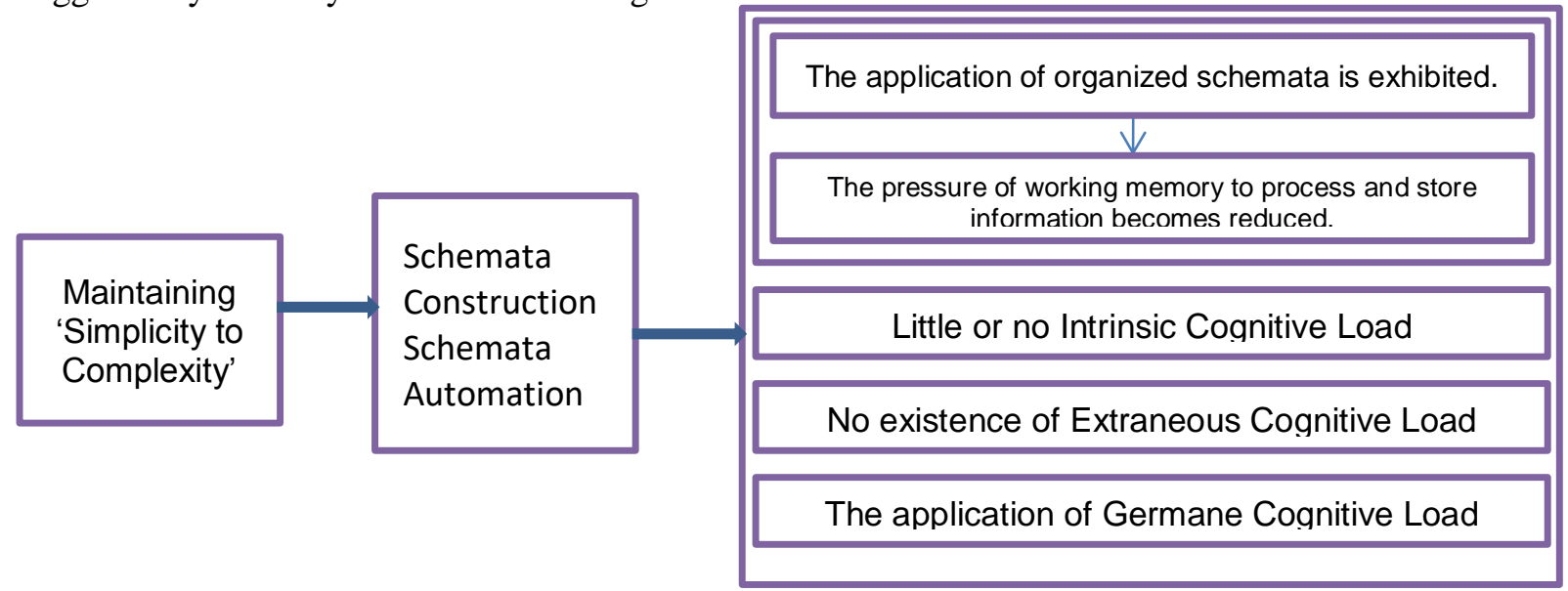

Diagram 12: Online learning in 10 Minute School

We observe learners' enthusiasm throughout the session. The contribution of 10 Minute School can be manifestly realized by incorporating a closer look to the context, where it is functioning. Producing citizens equipped with the ability to keep pace with the changing world intrigues Bangladesh - an EFL context Ali (2014, as cited in Ali \& Walker, 2014) - to immerse its countrymen in English learning process. Rahman and Pandian (2018), incorporating World Bank's (2016) report, also maintain that reaching the world market necessitates human capital equipped with the ability to communicate in English. The prior need concerns the attainment of learners' accuracy in writing. It is of particular importance because Karim, Mohamed, Ismail, Shahed, Rahman and Haque (2018) uncover the terrific scenario when investigating into learners' errors in writing. Grammatical errors in writing are identified affluent in number, spelling meaningless sentences often. It also exacerbates students' performance in examination, given writing accounts $40 \%$ to $50 \%$ of the total marks in Higher Secondary Certificate (HSC) and Secondary School Certificate (SSC) examinations. To induce students to learn grammar, and thereby, reduce the erroneous writing, National Curriculum and Textbook Board (NCTB) introduces grammatical components that cover 60\% of the total marks in English Second Paper in both SSC and HSC examinations.

Yet Karim et al. (2018) delineate alarming scenario concerning writing, affecting drastically our next generation. It is the result of assigning inadequately trained English teachers to teach English in learners' most impressionable years, primary and secondary levels. Previous and concurrent training programs potentially fail to address the need of our teachers and reach the number of teachers they have committed to train (Karim, Mohamed \& Rahman 2017; Karim, Mohamed, Ismail \& Rahman, 2018).

On the other hand, 10 Minute School offers a dynamic compensation not just by providing online teaching but also by assigning skilled and passionate teachers who have the ability to spell interactive and interesting classes. It is noteworthy that our traditional classrooms are teacher-oriented, and thus, students' interaction is hardly seen (Karim, Mohamed \& Rahman, 2017). 
The strength of the current study lies on its theoretical ground which acted as the point of departure for the current study. Through such adaptation, we have attempted to prove that the 10 Minute School has developed its lesson plans considering certain factors. Consequently, the findings of the study have corroborated that 10 Minute School substantially conceived these factors, which e-learning suggests, when contriving its lessons for everyday teaching. Building on such finding, we can speculate the sustainability of the program.

\title{
CONCLUSION
}

Our modest intention in this article has not been to glorify the 10 Minute School, but to inform the world as to how a nation - embarking on attaining proficiency for its citizens in oral and written form - is being facilitated by such enterprise. The extent to which such online teaching is important can be embraced from our discussions with regard to our context. Any context like Bangladesh can, therefore, devise such online teaching and learning program in order to compensate the learning gap yielded by traditional classroom. We have carried out our scrutiny adapting CLT theory and its implication to elearning with a view to notify the world that online teaching and learning should be developed considering such elements. Although we observe the indulgence conveyed by the learners on the comment section under each class, further study should be carried out to uncover as to how learners have been coping with such changing patterns of language teaching and what improvement they have attained after participating on online class regularly. The findings of the futuristic research will notify the sustainability of such program.

\section{BIODATA and CONTACT ADDRESSES of AUTHORS}

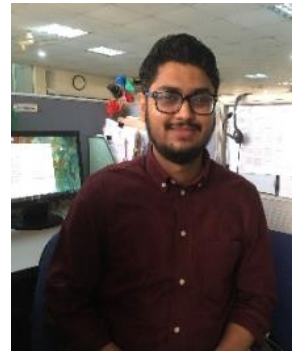

Abdul KARIM is a lecturer at BRAC Institute of Languages, BRAC University, Bangladesh. He has a Masters by Research in TESOL from Universiti Sains Malaysia. He has published widely in the field of English language teacher education in numerous international journals (Indexed in SCOPUS). He has been reviewing for many international journals in the field. Besides, he has developed instructional materials for the fundamental English language course for tertiary students.

\author{
Abdul KARIM \\ BRAC Institute of Languages \\ BRAC University \\ 66 Mohakhali, Dhaka 1212, Bangladesh \\ Tel: +8801821314486 \\ Email: khasan13aiub@gmail.com
}

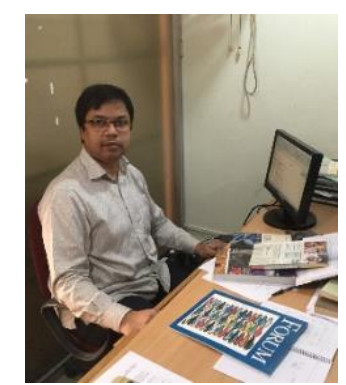

Dr. Faheem Hasan SHAHED is Professor and Head of 'MA in TESOL Program' at BRAC Institute of Languages in BRAC University, Dhaka. He achieved his M.Phil. (1998) and Ph.D. (2001) in Applied Linguistics from Jawaharlal Nehru University (JNU), India. Since then, he has been a full time academic, attaining wide expertise in teaching English to a diverse range of professionals over a span of 24 years. His area of interest includes ESAP, bilingualism, politics of language, culture \& gender aspects in ELT, Business Communication etc. and has published articles and book chapters in national and international journals.

Dr. Faheem Hasan SHAHED

BRAC Institute of Languages

BRAC University

66 Mohakhali, Dhaka 1212, Bangladesh

Tel: +8801821314486 


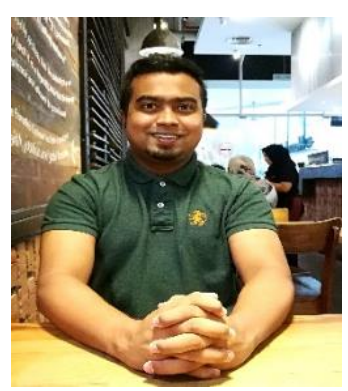

Mohammad Mosiur RAHMAN (MRes in Applied Linguistics) is a Ph.D. Fellow at School of Languages, Literacies and Translation, Universiti Sains Malaysia. His research interests are the interdisciplinary issues in language education and applied linguistics. His works have appeared in international journals with high impact factor/CiteScore such as English Today, Pertanika Journal of Social Sciences, Qualitative Report, The Journal of Asia TEFL, International Journal of Instruction, Turkish Online Journal of Distance Education and so on. He has peer-reviewed articles for renowned international journals like TESL-EJ, Asian EFL Journal and Compare: A Journal of Comparative and International education.

Mohammad Mosiur RAHMAN

School of Languages Literacies and Translation

Universiti Sains Malaysia

11800, Penang, Malaysia

TEL: +60164704423

Email:mosiurbhai@gmail.com

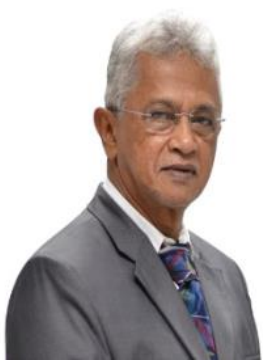

Dr. Abdul Rashid MOHAMED is a senior professor of education. He was a long time dean of the School of Educational Studies, Universiti Sains Malaysia from 2005 to 2015 and the Chairman of the Malaysian Education Deans' Council (from 2009-2015). Currently he is an advisor to the council. He is presently the deputy Chairman of the Malaysian Professorial Board (Education and Human Resource Cluster, since 2010). He also sits on a number of national and international levels committees on education. Among the roles he still plays are advisors to IDEC (Graduate School for International Development and Cooperation), Hiroshima University and Republic of Maldives Ministry of Education. He was the Chief editor of two journals until 2015; APJEE (Asia Pacific Journal of Educators and Education) and MEDC Journal (Malaysian Education Deans Council Journal). He is currently the Deputy Vice Chancellor of Albukhary International University, Malaysia.

Dr. Abdul Rashid MOHAMED

School of Educational Studies, Universiti Sains Malaysia

11800, Penang, Malaysia

TEL: +60124711531

Email: richsesusm@gmail.com

\section{REFERENCES}

Ali, M., \& Walker, A. L. (2014). 'Bogged down'ELT in Bangladesh: Problems and policy: Investigating some problems that encumber ELT in an EFL context. English Today, 30(2), 33-38.

Balcikanli, C. (2010). Long live, YouTube: L2 stories about YouTube in language learning. Annals of Language and Learning, 91.

Boonkit, K. (2011). Facebook: Bridging the Gap between Classroom English and Real World Reading for Non-Native Learners of English. International Journal of Arts \& Sciences, 4(18), 207225 .

Bradshaw, J., \& Hinton, L. (2004). Benefits of an Online Discussion List in a Traditional Distance Education Course. Online Submission, 5(3). 
Elo, S., \& Kyngäs, H. (2008). The qualitative content analysis process. Journal of advanced nursing, 62(1), 107-115.

Fisher, A., Exley, K., \& Ciobanu, D. (2014). Using technology to support learning and teaching. Routledge: New York.

Kabilan, M. K., Ahmad, N., \& Abidin, M. J. Z. (2010). Facebook: An online environment for learning of English in institutions of higher education?. The Internet and higher education, 13(4), 179-187.

Karim, A., Mohamed, A. R., \& Rahman, M. M. (2017). EIA-A Teacher Education Project in Bangladesh: An Analysis from Diversified Perspectives. International Journal of Instruction, 10(4), 51-66.

Karim, A., Mohamed, A. R., Rahman, M. M., \& Haque, M. H. (2017). Teachers' dilemma bog down CLT in EFL contexts: A discussion on EFL teachers' beliefs and sources. IOSR Journal of Humanities and Social Science (IOSR-JHSS), 22(4), 112-120.

Karim, A., Mohamed, A. R., \& Rahman, M. M. (2018). Organized Hypocrisy in EFL Teacher Training programs. International Journal of Instruction, 11(2), 437-450.

Karim, A., Mohamed, A. R., Ismail, S. A., Shahed, F. H., Rahman, M. M., \& Haque, M. H. (2018). Error Analysis in EFL Writing Classroom. International Journal of English Linguistics, 8(4), 122.

Manuel, J. T., \& P. Schunke, M. (2016). Meeting students where they are online, but leading them somewhere more interesting: Reflections on teaching the Facebook class. College Teaching, 64(3), 112-118.

McCarthy, J. (2010). Blended learning environments: Using social networking sites to enhance the first year experience. Australasian Journal of Educational Technology, 26(6).

Moir, S. (2010). Social Media Marketing Business Advantages of Facebook vs. Twitter Part 4.(Online).

Heiberger, G., \& Junco, R. (2011). Meet your students where they are: social media. NEA Higher Education Advocate, 28(5), 6-9.

Pimmer, C., Linxen, S., \& Gröhbiel, U. (2012). Facebook as a learning tool? A case study on the appropriation of social network sites from mobile phones in developing countries. British Journal of Educational Technology, 43(5), 726-738.

Rahman, M. M., \& Pandian, A. (2018). A Critical Investigation of English Language Teaching Bangladesh: Unfulfilled expectations after two decades of Communicative Language Teaching. English Today,17.

Red, D. (2009). The Advantages of Facebook.

Ru-Chu, S. H. I. H. (2013). Effect of using Facebook to assist English for business communication course instruction. Tojet: the Turkish online journal of educational technology, 12(1).

Simpson, J. (2017, June). Using Facebook in an EFL Business English Writing Class in a Thai University: Did It Improve Students' Writing Skills?. In Proceedings Education and Language International Conference (Vol. 1, No. 1).

Sweller, J. (2004). Instructional design consequences of an analogy between evolution by natural selection and human cognitive architecture. Instructional science, 32(1-2), 9-31.

Stone, B. (2006). Web of Risks. Newsweek. August 21, 2006. P. 76.

Tina, L. I. M. (2010). The use of Facebook for online discussions among distance learners. Turkish Online Journal of Distance Education, 11(4). 
Van Merriënboer, J. J., \& Ayres, P. (2005). Research on cognitive load theory and its design implications for e-learning. Educational Technology Research and Development, 53(3), 513.

Watted, A., \& Barak, M. (2018). Motivating factors of MOOC completers: Comparing between university-affiliated students and general participants. The Internet and Higher Education, $37,11-20$.

World Bank. 2016. 'GDP growth (annual \%).' Online at http://data.worldback.org/indicator/NY.GDP.MKTP.KD.ZG?page=1 (Accessed February 14, 2016).

Zhang, D., Zhao, J. L., Zhou, L., \& Nunamaker Jr, J. F. (2004). Can e-learning replace classroom learning?. Communications of the ACM, 47(5), 75-79. 